\title{
Cardiac Architecture
}

\author{
Alana Kelsall
}

foundations are laid out with such untidy corners the tricky bits not quite sewn in and then we grow bones stiffen like timber frames rising from vacant lots of land how confidently some little girls walk with their head up flicking their pony tails back look at me l'm walking with teacher

however many times I consult the forecast

each day births with its own slant I pick my way through maybe the tea leaves had more to say

than I thought back in Mum's kitchen so long ago the mind is full of pouches swelling into dead ends or a bud with the dew still on it what does weathered mean I thought I might wake and find there's been a harvest a sea horse or two for the return of the shipwrecked and plane-lost what else is there for the bereaved other than defensive manoeuvres wishing the earth flat like a bridge to somewhere else it matters who you choose to spend the rest of your life with

will we be sitting out there in the backyard one arm like a blunt wing waiting for summer how many people have you met that you've really liked and you thought the choice was yours to make 